\title{
Rethinking Manure Application: Increase in Multidrug-Resistant Enterococcus spp. in Agricultural Soil Following Chicken Litter Application
}

\author{
Dorcas Oladayo Fatoba ${ }^{1,2, * \mathbb{C}}$, Akebe Luther King Abia ${ }^{1, * \mathbb{C}}$, Daniel G. Amoako ${ }^{1}$ and Sabiha Y. Essack ${ }^{1} \mathbb{D}$ \\ 1 Antimicrobial Research Unit, College of Health Science, University of KwaZulu-Natal, Private Bag X54001, \\ Durban 4000, South Africa; amoakodg@gmail.com (D.G.A.); essacks@ukzn.ac.za (S.Y.E.) \\ 2 Department of Medical Microbiology, School of Laboratory Medicine and Medical Sciences, \\ University of KwaZulu-Natal, Durban 4000, South Africa \\ * Correspondence: dorcas4c@gmail.com (D.O.F.); lutherkinga@yahoo.fr (A.L.K.A.)
}

check for updates

Citation: Fatoba, D.O.; Abia, A.L.K.; Amoako, D.G.; Essack, S.Y.

Rethinking Manure Application:

Increase in Multidrug-Resistant

Enterococcus spp. in Agricultural Soil Following Chicken Litter Application. Microorganisms 2021, 9, 885 .

https://doi.org/10.3390/

microorganisms 9050885

Academic Editor: Elisa Gamalero

Received: 17 March 2021

Accepted: 7 April 2021

Published: 21 April 2021

Publisher's Note: MDPI stays neutral with regard to jurisdictional claims in published maps and institutional affiliations.

Copyright: (C) 2021 by the authors. Licensee MDPI, Basel, Switzerland. This article is an open access article distributed under the terms and conditions of the Creative Commons Attribution (CC BY) license (https:/ / creativecommons.org/licenses/by/ $4.0 /)$.

\begin{abstract}
The current study investigated the impact of chicken litter application on the abundance of multidrug-resistant Enterococcus spp. in agricultural soil. Soil samples were collected from five different strategic places on a sugarcane farm before and after manure application for four months. Chicken litter samples were also collected. Enterococci were enumerated using the Enterolert ${ }^{\circledR} /$ Quanti-Tray $2000^{\circledR}$ system and confirm and differentiated into species using real-time PCR. The antibiotic susceptibility profile of the isolates was determined using the disk diffusion method following the European Committee on Antimicrobial Susceptibility Testing (EUCAST) guidelines. The overall mean bacterial count was significantly higher $(p<0.05)$ in manure-amended soil $\left(3.87 \times 10^{7} \mathrm{MPN} / \mathrm{g}\right)$ than unamended soil $\left(2.89 \times 10^{7} \mathrm{MPN} / \mathrm{g}\right)$. Eight hundred and thirty-five enterococci ( 680 from soil and 155 from litter) were isolated, with E. casseliflavus being the most prevalent species $(469 ; 56.2 \%)$ and E. gallinarum being the least $(16 ; 1.2 \%)$. Approximately $56 \%$ of all the isolates were resistant to at least one antibiotic tested, with the highest resistance observed against tetracycline $(33 \%)$ and the lowest against chloramphenicol $(0.1 \%) ; 17 \%$ of E. faecium were resistant to quinupristin-dalfopristin. Additionally, 27.9\% (130/466) of the isolates were multidrug-resistant, with litter-amended soil harbouring more multidrug-resistant (MDR) isolates $(67.7 \%$; $88 / 130)$ than unamended soil $(10.0 \%$; 13/130). All isolates were susceptible to tigecycline, linezolid and gentamicin. About $7 \%$ of the isolates had a multiple antimicrobial resistance index $>0.2$, indicative of high antibiotic exposure. Although organic fertilizers are regarded as eco-friendly compared to chemical fertilizers for improving soil fertility, the application of untreated animal manure could promote the accumulation of antibiotics and their residues and antibiotic-resistant bacteria in the soil, creating an environmental reservoir of antimicrobial resistance, with potential human and environmental health risks.
\end{abstract}

Keywords: animal manure; antibiotic resistance; Enterococcus spp.; chicken litter; environmental reservoirs; multidrug resistance; public health; agricultural soil

\section{Introduction}

Poor soil fertility is a significant challenge for small and large-scale farming systems in sub-Saharan Africa, and chemical and organic fertilizers are frequently added to soil to improve its quality, texture, and crop yield [1]. However, chemical fertilizers affect beneficial microorganisms in the soil, cause an imbalance in soil $\mathrm{pH}$, contaminate groundwater through leaching without fully benefiting plants, and cause plant disease [2]. On the other hand, organic manure adds nutrient-rich organic matter, which improves soil fertility, texture, water-holding capacity, and imparts resistance to wind and water erosion $[3,4]$. Thus, applying animal manure to soil has become common in agricultural farms in many countries, including South Africa [1,5], as it improves soil properties and increases productivity [6]. 
Although the use of antibiotics in livestock farming has proven to be beneficial for economic reasons, their use as growth promoters for prophylaxis, metaphylaxis and treatment establishes a reservoir of antibiotic-resistant bacteria (ARB), including multidrug-resistant (MDR) ones and antibiotic resistance genes (ARGs) in the gastrointestinal tract of livestock, and subsequently their waste [7]. The addition of such animal waste as manure to the soil, without treatment, may contribute to the transmission of antibiotic resistance to soil bacteria and pose serious environmental risks [8]. This agricultural practice has resulted in the contamination of soil, surface water, groundwater, and the food chain with antibiotic residues and ARB, posing a severe public health concern associated with farm produce such as raw vegetables $[5,9]$.

Enterococci are Gram-positive natural commensals inhabiting humans and animals' digestive systems with a wide range of species such as E. faecalis, E. faecium, E. casseliflavus, E. gallinarum, E. durans, E. munditi, E. hirae, and E. avium [10]. The abundance of Enterococcus spp. in animal and human faeces and their prolonged survival in the environment have made them a popular indicator of faecal contamination in the environment [11,12]. Although considered a commensal in humans, certain Enterococcus species have been identified as high-ranking (second to staphylococci) agents causing nosocomial infections in humans [13]. These bacteria, especially multidrug resistance ones, in animal manure applied to agricultural fields represent a significant environmental and public health concern that needs considerable attention through continuous monitoring.

Therefore, this study investigated the prevalence of antibiotic-resistant Enterococcus spp. in soil amended with chicken litter on a sugarcane farm in KwaZulu-Natal, South Africa. Such information would guide decision making regarding the use of manure and emphasise the importance of antibiotic stewardship in agricultural practices, thus protecting human and environmental health.

\section{Materials and Methods}

\subsection{Ethical Clearance}

This study was part of a larger project for which ethical approval had been received from the Animal Research Ethics Committee (Reference: AREC073/016PD) and the Biomedical Research Ethics Committee (Reference: BCA444/16) of the University of KwaZuluNatal. The study was also approved by the South African National Department of Agriculture, Forestry, and Fisheries (Reference: 12/11/1/5 (879).

\subsection{Study Location}

This study was carried out for four months, between October 2018 and February 2019, on a sugarcane farm in the uMgungundlovu District, KwaZulu-Natal, South Africa (Figure 1). The district has a population of 1,069,657, with a population density of 110.7 persons $/ \mathrm{km}^{2}$. The area is home to the bulk of food animal production firms (pigs and poultry) and agriculture, mainly sugarcane, pear, and vegetable farms. Some of the water bodies around the farm in this locality include Mqeku, Mkabela, Mbhava, and Sterkspruit, which are small rivers that drain into the main Umgeni River (the primary source of drinking water for the people living in Pietermaritzburg). The sugarcane is planted between September and November and becomes fully mature in about 12 to 14 months. Soil amendment with chicken litter (a mix of chicken manure and wood shavings) is a common agricultural practice in the locality because of its availability, cost-effectiveness, and efficiency in improving soil quality. Chicken litter is usually randomly spread over the soil surface about ten days before planting. Urea is also applied to the soil seven days after manure application. 


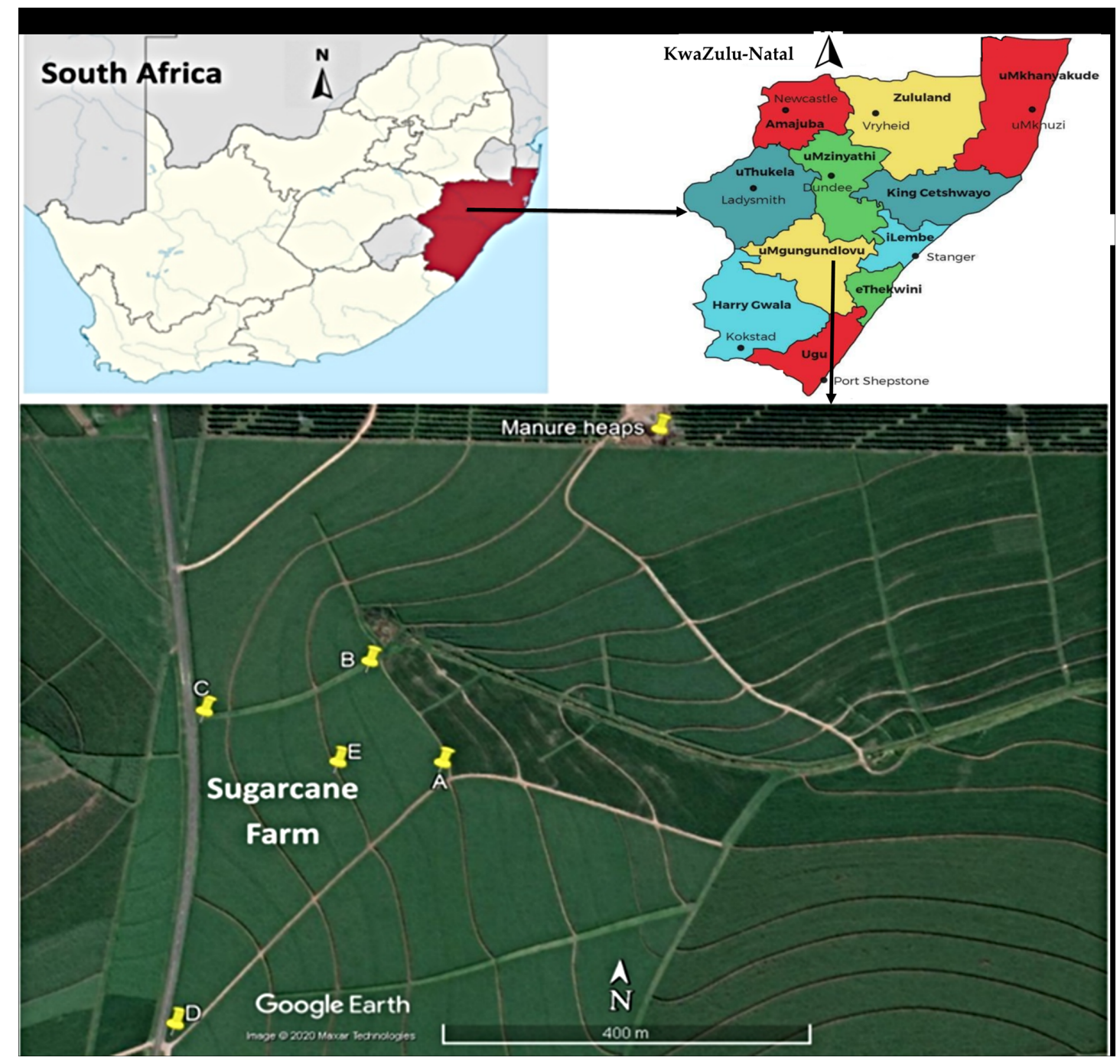

Figure 1. Map of the study site, including the sampling points (A, B, C, D, E and manure heap). Source: Google Earth.

\subsection{Sample Collection}

Soil samples were collected from five points of the sugarcane farm (Figure 1) on days $1,2,3,5$, and 9 before manure application. Following manure application, samples were collected on the day of application (day 0), then days 1, 3, 7, 14, 21, and bi-monthly after that for three months after the chicken litter application. Samples were collected until the farm became inaccessible due to the height of the plants.

Using a sterile hand shovel, $\approx 50 \mathrm{~g}$ of soil was aseptically collected within the top $5 \mathrm{~cm}$ of the soil and transferred into sterile ziplock bags. The same quantity of chicken litter was also collected from a heap of unapplied manure around the farm (Figure 1). All the soil samples were collected in duplicates and the chicken manure in triplicates. Samples were transported on ice packs to the laboratory for analyses within $6 \mathrm{~h}$ from collection. A total of 275 samples (82 chicken litter and 193 soil) were collected throughout the study.

\subsection{Sample Processing and Enumeration of Enterococcus spp.}

The Enterolert ${ }^{\circledR}-18^{\circledR}$ Quanti-Tray ${ }^{\circledR} / 2000$ system (IDEXX Laboratories (Pty) Limited, Totowa, NJ, United States) was used to enumerate Enterococcus spp. Soil and chicken litter samples were processed for analysis, as previously described by Abia et al. [14]. Briefly, $5 \mathrm{~g}$ of sample was transferred from a well-shaken zip-lock bag into a sterile bottle containing $5 \mathrm{~mL}$ of sterile distilled water, giving a 1:1 $(v / v)$ dilution. The mixture was shaken vigorously to dislodge the bacteria from the soil into the water. The bottle was 
allowed to settle for $20 \mathrm{~min}$, and $1 \mathrm{~mL}$ of the supernatant was extracted, topped up to $100 \mathrm{~mL}$ with sterile distilled water, and processed following the IDEXX protocol for water sample analysis (IDEXX Laboratories (Pty) Ltd., Johannesburg, South Africa). Ten positive wells in the quanti-tray (those that fluoresced under the UV light) were randomly picked, and their content was streaked onto Bile Aesculin agar plates (Lab M, Lancashire, UK) and incubated at $44 \pm 0.5{ }^{\circ} \mathrm{C}$ for $24 \mathrm{~h}$ to obtained pure colonies. One pure isolate was collected per plate and stored in Trypticase soy broth (Oxiod, Hampshire, England) with $20 \%$ glycerol at $-80^{\circ} \mathrm{C}$ for further analysis.

\subsection{DNA Extraction, Molecular Confirmation and Differentiation Enterococcus Species}

Stored isolates were resuscitated by culturing them on nutrient agar (Lab M, Lancashire, UK) at $41^{\circ} \mathrm{C}$ for $24 \mathrm{~h}$. Colonies were then transferred to sterile Eppendorf tubes containing $200 \mu \mathrm{L}$ of sterile distilled water and the DNA was extracted using the boiling method as previously described [15]. The supernatant was then used as the DNA template for the PCR assays.

Real-time polymerase chain reaction (RT-PCR) was used to confirm the isolates to genus level and distinguish between the species on a QuantStudio ${ }^{\circledR} 5$ Applied Biosystems (Applied Biosystems, ThermoFisher, Waltman, MA, USA) real-time PCR machine. The confirmation to genus level was carried out by targeting the tuf gene [16], using cycling conditions previously described by Molechan et al. [17]. All the confirmed Enterococcus isolates were further screened to speciate them as E. casseliflavus, E. faecalis, E. faecium, and E. gallinarum, using species-specific primers (Table S1) and PCR conditions previously described [17]. Enterococcus isolates that did not fall within the four species categories were tagged as Enterococcus spp. All primers were supplied by Inqaba Biotech Industries Ltd., Pretoria, South Africa. All reactions contained a positive control (Table S1) and a No Template Control (reaction mixture but no DNA). Melt curves were analysed using the QuantStudio $^{\mathrm{TM}}$ Design and Analysis Software v.1.3.1 (Applied Biosystems, ThermoFisher Waltman, MA, USA).

\subsection{Antibiotic Susceptibility Testing}

The confirmed Enterococcus isolates were subjected to antibiotic susceptibility testing using the disk diffusion method on Mueller-Hinton agar (Lab M, Lancashire, UK) according to the Clinical and Laboratory Standards Institute [18] and the European Committee on Antimicrobial Susceptibility Testing (EUCAST) [19] for breakpoints absent in the CLSI guidelines. The isolates were tested against 16 antibiotics in 12 antibiotic classes. These included ampicillin (AMP, $10 \mu \mathrm{g}$ ), teicoplanin (TEC, $30 \mu \mathrm{g}$ ), vancomycin (VAN, $30 \mu \mathrm{g}$ ), streptomycin (STR, $300 \mu \mathrm{g}$ ), linezolid (LZD, $30 \mu \mathrm{g})$, imipenem (IPM, $10 \mu \mathrm{g})$, erythromycin (ERY, $15 \mu \mathrm{g}$ ), ciprofloxacin (CIP, $5 \mu \mathrm{g}$ ), levofloxacin (LEV, $5 \mu \mathrm{g}$ ), nitrofurantoin (NIT, $300 \mu \mathrm{g}$ ), gentamicin (GEN, $120 \mu \mathrm{g})$, chloramphenicol (CHL, $30 \mu \mathrm{g})$, sulfamethoxazole-trimethoprim (SXT, $25 \mu \mathrm{g}$ ), tetracycline (TET, $30 \mu \mathrm{g}$ ) and tigecycline (TGC, $15 \mu \mathrm{g}$ ) (Oxoid, Hampshire, England). E. faecium was additionally tested against quinupristin-dalfopristin (QD, $15 \mu \mathrm{g})$. E. faecalis ATCC 29,212 was used as a positive control. The inhibition zones' diameters were measured in millimetres and interpreted as susceptible (S), intermediate (I), or resistant (R) [18]. EUCAST was used for three antibiotics (TGC, $15 \mu \mathrm{g}, \mathrm{SXT}, 25 \mu \mathrm{g}$, and IMP, $10 \mu \mathrm{g}$ ). Isolates resistant to one or more antibiotics in three or more different antibiotics classes were classified as MDR.

The multiple antibiotic resistance index (MARI) of each isolate was calculated as a/b (a: number of antibiotics to which the isolates were resistant, b: number of antibiotics against which the isolates were tested) [20]. The MARI of each sample group was calculated using the formula a/(bc), where "a" represents the aggregate antibiotic resistance score of all Enterococcus isolates from each sample group, " $b$ " is the number of antibiotics tested against the isolates, and " $c$ " represents the total number of isolates per sample group [20]. 


\subsection{Data Analysis}

All statistical analyses were performed using Microsoft Excel 2016 and the Statistical Package for the Social Science (SPSS v26, IBM Corporation, Armonk, NY, USA). Before analysis, enterococci counts were log-transformed, and the geometric means were used to describe the microbial concentration in soil and chicken litter. To calculate the log counts and the geometric means, all values $>2419.6$ were approximated to the nearest whole number (2420), and values $<1$ were considered as 1 . One-way analysis of variance (ANOVA) and the Games-Howell post hoc test were conducted to compare the mean Enterococcus counts and the number of antibiotic-resistant species between the chicken litter, litter-amended soil and soil samples collected before litter application. Results were considered statistically significant if the $p$-value was $<0.05$.

\section{Results}

3.1. Quantification of Enterococcus spp.

All the soil and chicken litter samples from the various sample groups and points tested positive for Enterococcus. The highest mean count $\left(5.68 \times 10^{7} \mathrm{MPN} / \mathrm{g}\right)$ per sample round was observed in the chicken litter (Table S2). The overall mean bacterial count was higher in litter-amended soil $\left(3.87 \times 10^{7} \mathrm{MPN} / \mathrm{g}\right)$ than unamended soil $\left(2.89 \times 10^{7} \mathrm{MPN} / \mathrm{g}\right)$ (Figure 2).

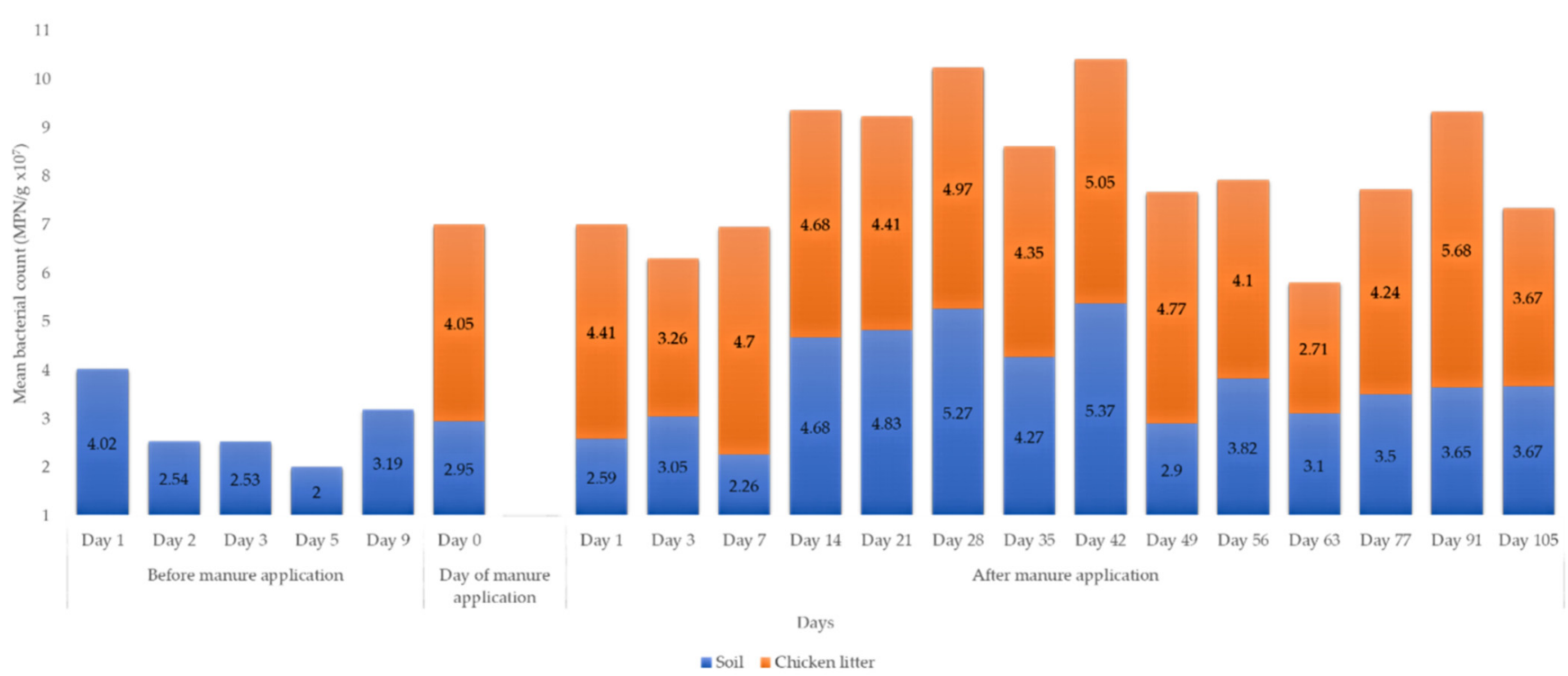

Figure 2. Mean Enterococcus spp. count per sampling source and sampling day. No litter sample collected before the litter application. The farm was burnt on day 2 in preparation for harvest. Rainfall events were recorded on day 3 (before litter application) and day 14, 42 and 77 after the litter amendment. Urea was applied to the farm on day 7.

There was an overall statistically significant difference $(p=0.000 ; p<0.05)$ in Enterococcus count between the three sample groups (Table 1). Games-Howell post hoc test indicated that the overall Enterococcus mean count in the chicken litter was significantly higher than the litter-amended soil $(p=0.01, p<0.05)$, and unamended soil $(p<0.001$, $p<0.05)$. A statistically significantly higher mean Enterococcus count was observed in the litter-amended soil than unamended soil $(p=0.01, p<0.05)$.

\subsection{Prevalence of Enterococcus spp. Isolates in Soil and Chicken Litter}

A total of 835 enterococci (680 from soil and 155 from chicken litter) isolates were confirmed. E. casseliflavus was the most prevalent species (56.17\%), and E. gallinarum as the least prevalent (1.9\%) (Figure 3). E. faecium and E. gallinarium were not detected in unamended soil samples; $12.2 \%$ of the isolates could not be classified into any of the four Enterococcus species. 
Table 1. Statistical comparison of mean Enterococcus counts between sample sources.

\begin{tabular}{|c|c|c|c|c|c|c|c|c|}
\hline \multirow{2}{*}{ Group } & \multirow{2}{*}{$\mathbf{N}$} & \multirow{2}{*}{$\begin{array}{l}\text { Overall Mean Enterococcus } \\
\text { Count (MPN/g } \times 10^{7} \text { ) }\end{array}$} & \multirow{2}{*}{ Overall $p$-Value } & \multicolumn{2}{|c|}{$\begin{array}{l}\text { Pair Wise Comparison } \\
\text { (Games-Howell) }\end{array}$} & \multicolumn{2}{|c|}{$\begin{array}{l}95 \% \text { Confidence Interval for Mean } \\
(\log \text { MPN/g) }\end{array}$} & \multirow{2}{*}{$p$-Value } \\
\hline & & & & & Mean Difference ( \pm SE) & Lower Bound & Upper Bound & \\
\hline SBL & 48 & $2.89( \pm 0.92) *$ & \multirow{3}{*}{$0.000^{* * *}$} & SBL vs. LAS & $-0.98( \pm 1.18)^{*}$ & -1.40 & -0.57 & $0.000 *$ \\
\hline LAS & 145 & $3.87( \pm 1.43) *$ & & SBL vs. CL & $-1.52( \pm 0.19) *$ & -1.98 & -1.06 & 0.000 * \\
\hline CL & 44 & $4.41( \pm 0.92) *$ & & LAS vs. CL & $-0.54( \pm 1.18) *$ & -0.97 & -0.10 & $0.011 *$ \\
\hline
\end{tabular}

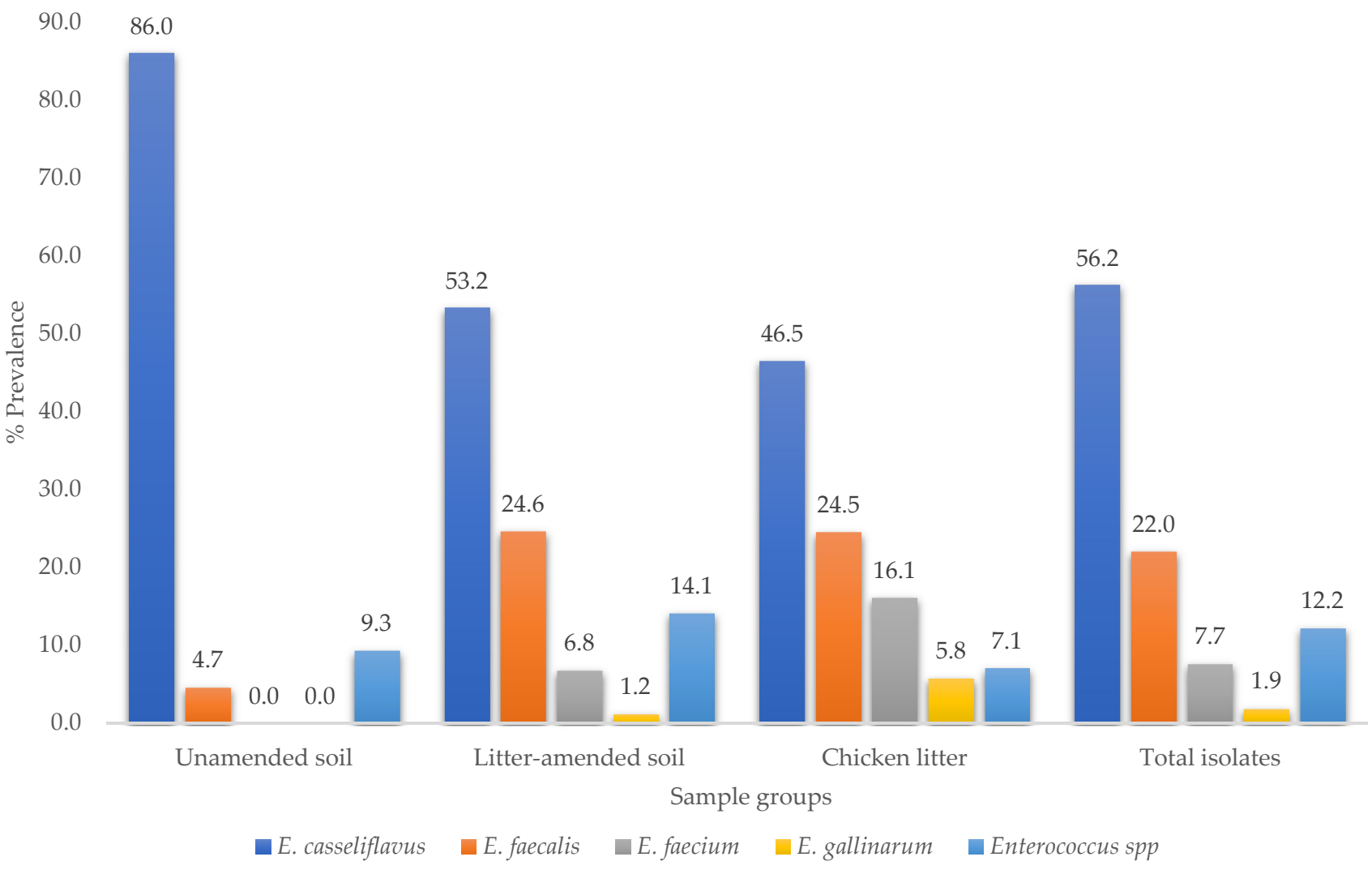

Figure 3. Distribution of Enterococcus spp. across sample types. 


\subsection{Antibiotic Susceptibility Profiles of Enterococcus spp.}

Overall, 466 (55.8\%) of 835 Enterococcus isolates in this study were resistant to at least one antibiotic, of which 321 (68.9\%) were from litter-amended soil, 93 (19.9\%) from chicken litter, and $52(11.2 \%)$ from unamended. Overall, the highest resistance observed was against tetracycline $(58.2 \%)$ and the lowest against chloramphenicol (0.2\%) (Figure 4$)$. None of the isolates were resistant to tigecycline, linezolid, and gentamicin. The variation in the number of resistant isolates with sampling days is shown in Figure S1 (Supplementary Materials). The susceptibility profile of quinupristin-dalfopristin was only reported for E. faecium, and $19 \%$ were resistant isolates. Only E. casseliflavus (2\%) and E. gallinarum $(4 \%)$ species showed resistance to vancomycin while E. faecalis $(7 \%)$ were of intermediate susceptibility (Table S3; Supplementary Materials).

Although there was an overall increase in the number of resistant isolates following the chicken litter amendment, this was not statistically significant (Table 2) in the number of resistant isolated between the three sample groups.

\subsection{Prevalence of Multidrug Resistance and Calculation of MARI}

Multidrug resistance was observed in $27.8 \%(130 / 466)$ of the resistant enterococci isolates. Among these MDR, the litter-amended soil isolates had the highest percentage, $67.7 \%(88 / 130)$, followed by the chicken litter $22.3 \%$ (29/130) and unamended soil $10 \%$ $(13 / 130)$ (Table S3). The division of the MDR into species revealed that E. faecium had the highest rate $(41 \%, 26 / 64)$ of MDR compared to other species, with the least MDR observed in E. faecalis $(13 \%, 23 / 184)$.

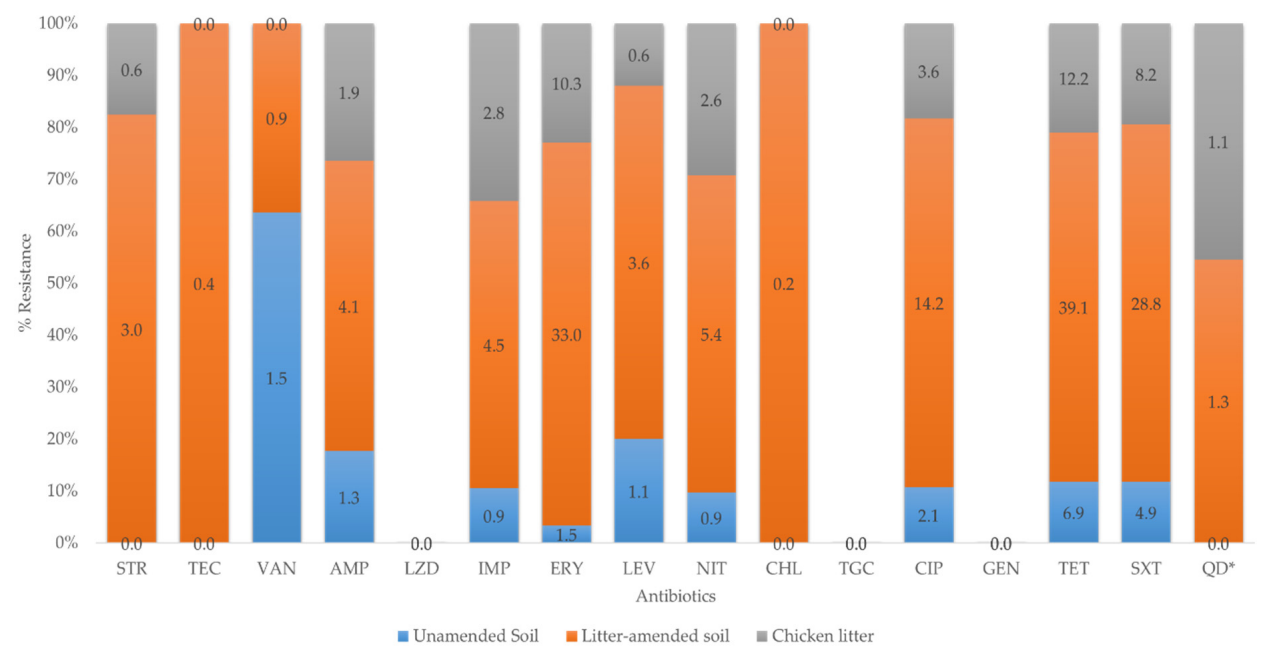

Figure 4. Prevalence of antibiotic-resistant Enterococcus in the soil and chicken litter. AMP = ampicillin, TGC = tigecycline, TET = tetracycline, $\mathrm{CHL}=$ chloramphenicol, GEN = gentamicin, TEC = teicoplanin, VAN = vancomycin, STR = streptomycin, LZD = linezolid, IPM = imipenem ERY = erythromycin, $\mathrm{CIP}=$ ciprofloxacin, $\mathrm{LEV}=$ levofloxacin, NIT = nitrofurantoin, SXT = sulfamethoxazole/trimethoprim, $\mathrm{QD}=$ quinupristin-dalfopristin. $\mathrm{QD}^{*}$ is reported only for $E$. faecium isolates.

Overall, 63 MDR patterns were observed across the enterococci isolates, the most prevalent phenotype being ERY-TET-SXT (Table S3). At the species level, E. casseliflavus, E. faecium, E. faecalis, other Enterococcus spp. and E. gallinarum showed 40, 23, 12, and 12 MDR patterns, respectively.

The isolates' MAR indices ranged from 0.13 (resistance to two antibiotics) to 0.44 (resistance to seven antibiotics) (Figure 5). In total, 12.1\% (56/466) of the resistant isolates had a MARI > 0.2. Of these, $58.9 \%(33 / 56)$ was from the litter-amended, $26.8 \%(15 / 56)$ of the isolates from the chicken litter, and $14.3 \%(8 / 56)$ from the soil before the litter amendment. The average MAR indices value according to the sample groups revealed that the chicken litter had the highest value of 0.09 compared to the litter-amended soil (0.08) and the soil samples before litter-amendment (0.06) (Table S4). 
Table 2. Statistical comparison of the prevalence of resistant-Enterococcus isolates between sample sources.

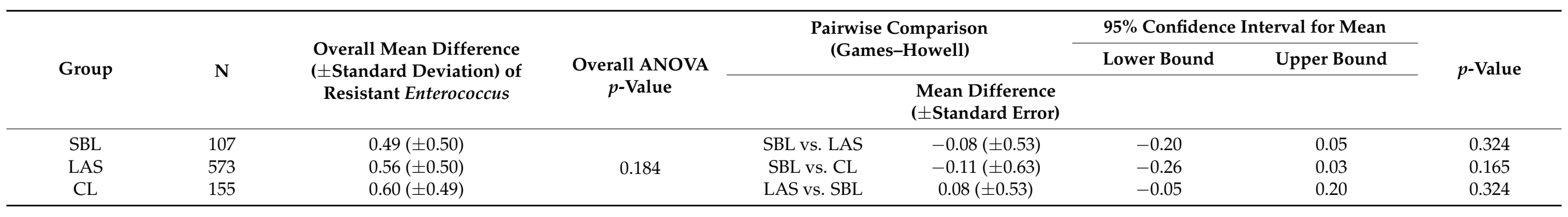

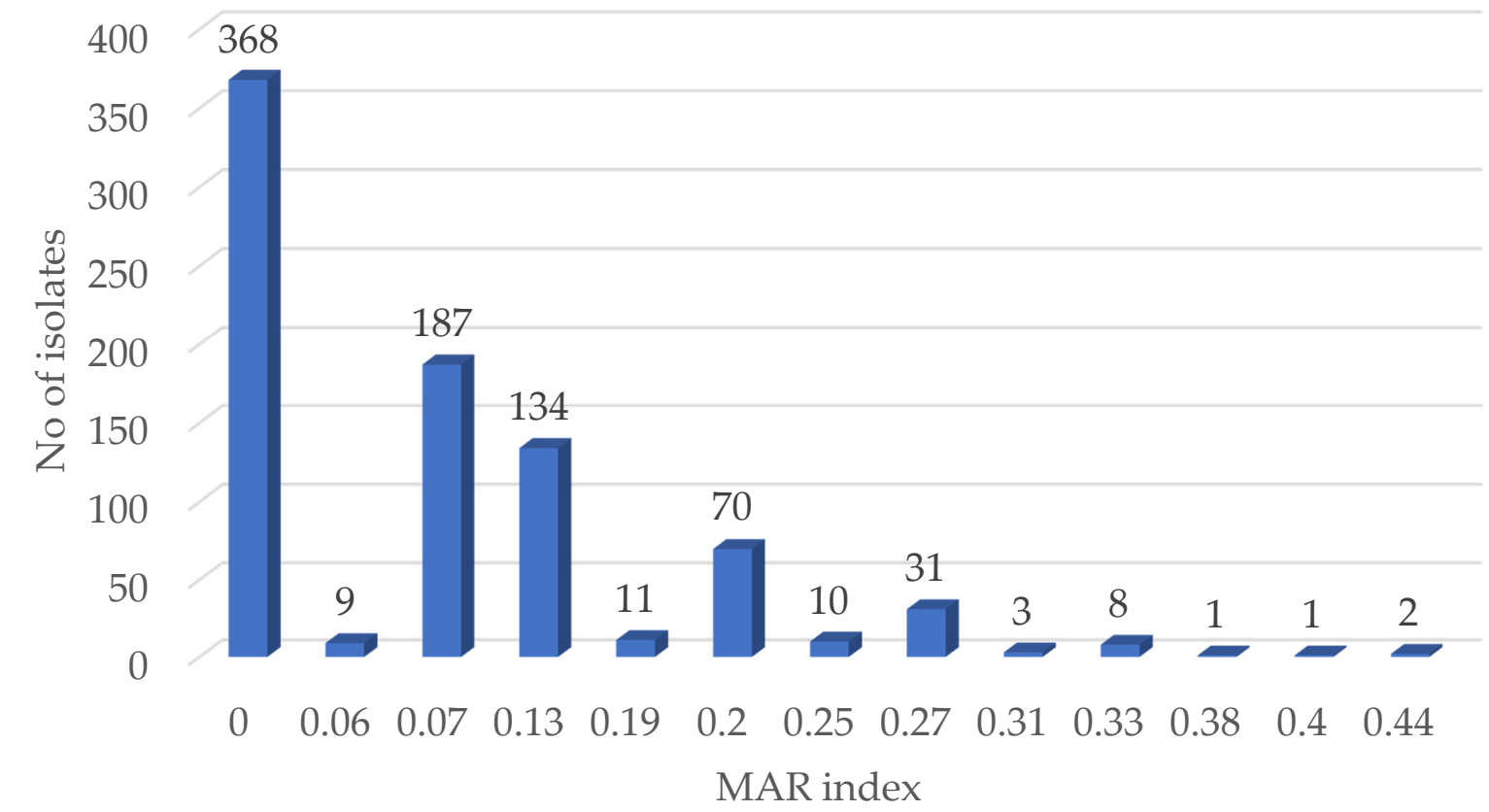

Figure 5. Multiple antibiotic resistance (MAR) indices of all the Enterococcus isolates. 


\section{Discussion}

Although animal manure is regarded as an organic approach to soil fertility improvement, its application to soil may introduce numerous ARB to the environment. Thus, we investigated the impact of chicken litter application on the prevalence of antibiotic-resistant Enterococcus spp. in agricultural soils. There was a marked increase in Enterococcus counts in the soil following manure application, with some species only identified in manureamended soils and chicken litter but not in the soil before manure application. The Enterococcus spp. were resistant to tetracycline, erythromycin, trimethoprim-sulfamethoxazole, and fluoroquinolone, commonly used in poultry production in South Africa. Approximately $28 \%$ of the resistant enterococci were MDR, with a substantial percentage of them having a MARI $>0.2$.

\subsection{Enumeration of Enterococcus before and after Manure Application}

Enterococcus has been widely used as a faecal bacterial indicator in the environment. In the current study, the mean Enterococcus count in the litter-amended soil was statistically significantly higher than in the soil before amendment (Table 1), indicating that manure application impacted the soil bacterial abundance. This could have happened in two ways. Firstly, chicken manure is exceptionally nutrient-rich, and its application on the farm resulted in the enrichment of indigenous bacteria, including Enterococcus. The use of animal manure for soil fertilization has been shown to enhance resident soil bacteria's proliferation in agricultural soil [21]. Secondly, Enterococcus is a normal flora of human and animal intestines [11,12]. Therefore, manure application resulted in the direct introduction of Enterococcus into the soil. The second argument is supported by the fact that the chicken litter recorded a statistically significantly higher bacterial count than the soil before manure application and manure-amended soil. Consistent with our findings, Marti and colleagues [21] reported that soil fertilisation with swine and dairy manure increased the count of viable bacteria in the soil.

Although there were fluctuations in the Enterococcus counts during the different sampling rounds after chicken litter application, an overall decline to baseline values was observed by the last sampling date (day 105). Some studies have indicated that bacteria of animal manure origin only survive in the soil environment for a short period (days to few months) [22-24], while others have indicated that enterococci could persist in manured soil environments for up to a year [25]. Cools et al. [24] demonstrated that Enterococcus spp. derived from pig manure could survive in the soil for 54 days in a study conducted in Belgium. Contrarily, [25] reported in a USA study that enterococci concentration in the swine manured soil decreased to concentrations equivalent to the no-manure soil after one year of manure amendment. Therefore, although the sampling in the current study ended on day 105, the manure's effect could be felt far beyond the sampling period. This could explain the presence of Enterococcus in the soil before manure application in this study. The long-term persistence of enterococci in the litter-amended soil is worrying, as the potentially pathogenic strains could enter the food chain or get washed during rainfall events to nearby surface water bodies. This also implies that yearly manure application could maintain high enterococci concentrations in the soil environment, with potential environmental and human health implications.

\subsection{Prevalence of Different Enterococcus Species}

According to species, the molecular characterization of the enterococci revealed differences between the soil before and after the litter amendment. Although E. casseliflavus was present in all sample sources, its high prevalence and dominance in the soil before manure was expected as this species is plant-associated [26]. Similar findings had earlier been reported in the USA [27]. Contrarily, there was a low E. faecalis prevalence in the soil before manure (Figure 3). No other species were identified in this soil. However, after manure application, the prevalence increased in the soil, indicating the manure's impact. Most importantly, E. faecium and E. gallinarum were only identified in the litter-amended soil. 
These species were absent in soil before manure application but present in the chicken-litter samples, further highlighting the chicken litter's significant impact on the soil Enterococcus abundance. These observations corroborate a field experiment in China, which observed a significant increase in bacterial diversity in soil following chicken manure amendment [28]. The appearance of E. faecium and E. gallinarum as well as the increased detection of E. faecalis, which are characteristic of warm-blooded animals in the soil after the litter amendment, implies that these two important human infectious agents may be potential indicators of transmission dynamics between the soil environment and humans, directly through exposure to contaminated soil or indirectly through consumption of poorly washed crops from manure fertilized farms.

\subsection{Antibiotic Resistance of Enterococcus Species}

Antibiotic-resistant Enterococcus spp. was detected in all the sample groups with the highest resistance percentage in the litter-amended soil (Figure 3). The isolates from the soil before amendment were mostly resistant to tetracycline and trimethoprim-sulfamethoxazole, while the litter-amended soil and chicken litter isolates expressed high-level resistance to tetracycline, erythromycin, and trimethoprim-sulfamethoxazole. The extensive administration of sub-therapeutic doses of antibiotics overtime in food animal production creates a selective advantage for the emergence of ARB in their intestines, which invariably ends up in manure and the environment [29-31]. This was reflected in the high percentage resistance to tetracycline, erythromycin, and trimethoprim-sulfamethoxazole among the litter-amended soil and the chicken litter enterococci isolates in the current study. These antibiotics or their homologues are used in the South African poultry industry [32], despite the prohibited use of several critically important antibiotics for humans in other parts of the world such as Europe [33]. The increased frequency of erythromycin-resistant enterococci in the soil after the litter amendment and the high intermediate susceptibility of the isolates to erythromycin and ciprofloxacin observed could have resulted from the addition of tylosin and enrofloxacin to the chicken's feed and water, and their use for treating infections in the animals [17,32]. A previous study on antibiotic-resistant enterococci in chicken litter in Canada reported a higher prevalence of resistance to tetracycline and ciprofloxacin [34], attributed to the large quantities of antibiotics used for growth promotion in broiler chicken farms [34]. Similarly, a previous study of antibiotic-resistant Enterococcus spp. from farm-to-fork conducted in uMgungudlovu District, South Africa, also indicated a higher level of resistance to tetracycline and erythromycin and high intermediate resistance to ciprofloxacin [17].

The literature has shown that animals excrete as much as $90 \%$ of the antibiotics administered orally or added to the feeds through faeces or urine [35]. Although the use of chicken litter as organic fertilizer is a common agricultural practice in South Africa [1], no previous study has examined the impact of chicken litter application on soil antimicrobial-resistant microorganisms in South Africa. In the current study however, the litter amendment increased the number of antibiotic-resistant enterococci in the soil, which could be attributed to the enrichment of resident resistant enterococci in the soil and the addition of resistant species directly to the soil. This is supported by the increase in the number of resistant enterococci in the soil on the day of chicken litter application (Figure S1; Supplementary Materials). Previous studies have reported animal manure as a reservoir of ARB and a source of environmental (soil) contamination with ARB $[9,26]$. For example, a study on agricultural soil fertilized with swine manure in Iowa State, USA, showed that the concentration of antibiotic-resistant enterococci in the soil with manure was greater than the control soil that was not treated with manure [25]. Similarly, a practical survey of ARB in chicken manure-amended soil and manure-free soil carried out in China reported a significantly higher prevalence of cultivable ARB in the manure-amended soil than the count in the manure-free soil samples [8].

Although the prevalence of resistant Enterococcus spp. was generally higher in the litter amended soil, this was not statistically significant (Table 2), as some external factors 
played a significant role. For example, a major reduction in the number of resistant Enterococci was observed on day 7 (after the chicken litter amendment), which happened to be the day urea was applied to the field. Urea application has been shown to decrease the soil microbial population and diversity [36,37]. The number of antibiotic-resistant enterococci in the litter-amended soil decreased to levels comparable to the soil resistance before amendment at 28 days after the chicken litter amendment, suggesting the depletion of manure nutrient that enhanced the growth of resident bacteria and the death of the litter-borne enterococci [38].

It should, however, be noted that there was also a high tetracycline and trimethoprimsulfamethoxazole percentage resistance observed in the soil before the chicken litter amendment. These antibiotics or their residues should also be considered regarding the selection pressure they may exert on soil bacterial populations. While some of the antibiotics such as erythromycin and tylosin completely biodegrade in soil within 30 days at $20{ }^{\circ} \mathrm{C}$ to $30{ }^{\circ} \mathrm{C}$, only a small amount of antibiotics such as ciprofloxacin, tetracycline, and some sulphonamides degrade even after 30 to 80 days $[35,39,40]$.

The MARI is used in differentiating between bacteria from low- and high-health risk sources. A MARI value greater than 0.2 indicates that such bacterial isolates originate from a source with high antibiotics use contamination [20]. The impact of manure on the presence of antibiotic-resistant Enterococcus spp. was further demonstrated here as isolates from the litter-amended soil had a higher percentage of isolates with a MARI $>0.20$. Additionally, although the sample groups' MAR indices were $<0.20$, the comparable MAR index of the chicken litter (0.09) and the litter-amended soil (0.08) suggests the transmission of ARB from sources of frequent antibiotic use, such as on intensively produced chicken as was the litter source here. Furtula and colleagues [34] reported high average MAR indices for the enterococci isolated from the chicken litter samples and attributed their observation to different antibiotic usage levels in the poultry systems from which the litter was sourced.

\section{Conclusions}

Chicken litter application increased the abundance and diversity of Enterococcus species in agricultural soil. There was also an increase in antibiotic-resistant enterococci species, including MDR ones, in the litter-amended soil, suggesting the possibility of the transfer of ARB in the chicken litter to the soil. This was further supported by the overall higher MARI of litter-amended soil than unamended soil. A higher percentage resistance was observed against tetracycline, erythromycin, and sulfamethoxazole-trimethoprim. A substantial number of the isolates from chicken litter shared similar resistance patterns to litter-amended soil isolates, suggesting a possible transfer of ARB (or ARGs) of chicken litter to the agricultural soil. The persistence of antibiotic-resistant enterococci species in the manured soil and the heap of chicken litter throughout this study highlights the risk of antibiotic resistance exposure when humans and animals consume contaminated farm produce. This study delineated chicken litter as a "hotspot" of antibiotic-resistant enterococci species that can contaminate the soil fertilized with it and pose a public health threat from its incorporation into plants, run-off to water sources and direct contact in occupationally exposed workers. It is, therefore, necessary to rethink the use of animal manure for soil fertilization. Since composting has been reported to reduce the number of ARB in animal manure, this should be carried out on chicken litter before its application to the soil to minimize soil contamination with ARB and reduce the possible dissemination of antibiotic resistance from chicken to farm produce. Policies on the prudent use of antibiotics in animal production is also required.

Supplementary Materials: The following are available online at https://www.mdpi.com/article/10 .3390 / microorganisms9050885/s1, Figure S1: Variation in antibiotic-resistant Enterococcus to at least one antibiotic throughout sample collection, Table S1: List of genus and species-specific primers and control strains used in this study, Table S2: Enumeration of Enterococcus in soil and chicken litter over the sampling period, Table S3: Multidrug-resistant pattern of the Enterococcus spp. isolates, Table S4: 
Percentage of Enterococcus isolates that were resistant to at least one antibiotic at each sample point and the multiple antibiotic resistance index.

Author Contributions: Conceptualisation, All; methodology, D.O.F.; validation, All; formal analysis, D.O.F., A.L.K.A. and D.G.A.; investigation, D.O.F.; resources, S.Y.E.; writing-original draft preparation, D.O.F.; writing-review and editing, All; supervision, A.L.K.A., and S.Y.E.; project administration, S.Y.E.; funding acquisition, S.Y.E. All authors have read and agreed to the published version of the manuscript.

Funding: This research was funded by the WHO Advisory Group on Integrated Surveillance of Antimicrobial Resistance (AGISAR) Research Project: "Triangulation of Antibiotic Resistance from Humans, the Food Chain and Associated Environments-A One Health Project" (Reference ID: 204517), South African Research Chair Initiative of the Department of Science and Technology and National Research Foundation of South Africa (Grant No. 98342), the South African Medical Research Council (SAMRC) and UK Medical Research Council, the SAMRC under a Self-Initiated Research Grant and the College of Health Sciences, University of Kwa-Zulu Natal, South Africa. Any opinions, findings, and conclusions, or recommendations expressed in this material are those of the author(s) and do not necessarily reflect the views of the organisations or agencies that provided support for the project. The funders had no role in the study design nor the decision to submit the work for publication.

Institutional Review Board Statement: Not applicable.

Informed Consent Statement: Not applicable.

Data Availability Statement: All data have been included in this manuscript.

Conflicts of Interest: Sabiha Y. Essack is the chairperson of the Global Respiratory Infection Partnership and member of the Global Hygiene Council, both sponsored by an unrestricted educational grant from Reckitt and Benckiser Ltd., UK. All other authors have no competing interests. The funders had no role in the study's design, collection, analyses, or interpretation of data, writing of the manuscript, or in the decision to publish the results.

\section{References}

1. Materechera, S.A. Utilization and management practices of animal manure for replenishing soil fertility among smallscale crop farmers in semi-arid farming districts of the North West Province, South Africa. Nutr. Cycl. Agroecosyst. 2010, 87, 415-428. [CrossRef]

2. Han, S.H.; An, J.Y.; Hwang, J.; Kim, S.B.; Park, B.B. The effects of organic manure and chemical fertilizer on the growth and nutrient concentrations of yellow poplar (Liriodendron tulipifera Lin.) in a nursery system. For. Sci. Technol. 2016, 12, 137-143.

3. Wang, X.; Yan, J.; Zhang, X.; Zhang, S.; Chen, Y. Organic manure input improves soil water and nutrients use for sustainable maize (Zea mays. L) productivity on the Loess Plateau. PLoS ONE 2020, 15, e0238042. [CrossRef] [PubMed]

4. Zhang, Z.; Dong, X.; Wang, S.; Pu, X. Benefits of organic manure combined with biochar amendments to cotton root growth and yield under continuous cropping systems in Xinjiang, China. Sci. Rep. 2020, 10, 1-10. [CrossRef] [PubMed]

5. Furtula, V.; Farrell, E.G.; Diarrassouba, F.; Rempel, H.; Pritchard, J.; Diarra, M.S. Veterinary pharmaceuticals and antibiotic resistance of Escherichia coli isolates in poultry litter from commercial farms and controlled feeding trials. Poult. Sci. 2010, 89, 180-188. [CrossRef] [PubMed]

6. Bhattacharyya, R.; Kundu, S.; Pandey, S.C.; Singh, K.P.; Gupta, H.S. Tillage and irrigation effects on crop yields and soil properties under the rice-wheat system in the Indian Himalayas. Agric. Water Manag. 2008, 95, 993-1002. [CrossRef]

7. Doyle, M.P.; Busta, F.; Cords, B.R.; Davidson, P.M.; Hawke, J.; Hurd, H.S.; Isaacson, R.E.; Matthews, K.; Maurer, J.; Meng, J.; et al. Antimicrobial resistance: Implications for the food system: An expert report, funded by the IFT Foundation. Compr. Rev. Food Sci. Food Saf. 2006, 5, 71-137.

8. Yang, Q.; Zhang, H.; Guo, Y.; Tian, T. Influence of chicken manure fertilization on antibiotic-resistant bacteria in soil and the endophytic bacteria of Pakchoi. Int. J. Environ. Res. Public Health 2016, 13, 662. [CrossRef]

9. Diarra, M.S.; Silversides, F.G.; Diarrassouba, F.; Pritchard, J.; Masson, L.; Brousseau, R.; Bonnet, C.; Delaquis, P.; Bach, S.; Skura, B.J.; et al. Impact of feed supplementation with antimicrobial agents on growth performance of broiler chickens, Clostridium perfringens and Enterococcus counts, and antibiotic resistance phenotypes and distribution of antimicrobial resistance determinants in Escheric. Appl. Environ. Microbiol. 2007, 73, 6566-6576. [CrossRef]

10. Haslam, D.B.; St. Geme, J.W. Enterococcus Species. In Principles and Practice of Pediatric Infectious Diseases; Long, S.S., Prober, C.G., Fischer, M., Eds.; Elsevier Inc.: Amsterdam, The Netherlands, 2018; pp. 729-732.e1.

11. D’Ugo, E.; Marcheggiani, S.; D'Angelo, A.M.; Caciolli, S.; Puccinelli, C.; Giuseppetti, R.; Marcoaldi, R.; Romanelli, C.; Mancini, L. Microbiological water quality in the medical device industry in Italy. Microchem. J. 2018, 136, 293-299. [CrossRef]

12. WHO. A Global Overview of National Regulations and Standards for Drinking-Water Quality. Verordnung über die Qual. t von Wasser für den Menschl. Gebrauch (Trinkwasserverordnung-TrinkwV 2001); World Health Organization: Geneva, Switzerland, 2018. 
13. Zhou, X.; Willems, R.J.L.; Friedrich, A.W.; Rossen, J.W.A.; Bathoorn, E. Enterococcus faecium: From microbiological insights to practical recommendations for infection control and diagnostics. Antimicrob. Resist. Infect. Control. 2020, 9, 1-13. [CrossRef]

14. Abia, A.L.K.; Ubomba-Jaswa, E.; Momba, M.N.B. Impact of seasonal variation on Escherichia coli concentrations in the riverbed sediments in the Apies River, South Africa. Sci. Total Environ. 2015, 537, 462-469. [CrossRef] [PubMed]

15. Yamagishi, J.; Sato, Y.; Shinozaki, N.; Ye, B.; Tsuboi, A.; Nagasaki, M.; Yamashita, R. Comparison of boiling and robotics automation method in DNA extraction for metagenomic sequencing of human oral microbes. PLoS ONE 2016, 11, e0154389. [CrossRef] [PubMed]

16. Ke, D.; Picard, F.J.; Martineau, F.; Ménard, C.; Roy, P.H.; Ouellette, M.; Bergeron, M.G. Development of a PCR assay for rapid detection of enterococci. J. Clin. Microbiol. 1999, 37, 3497-3503. [CrossRef] [PubMed]

17. Molechan, C.; Amoako, D.G.; Abia, A.L.K.; Somboro, A.M.; Bester, L.A.; Essack, S.Y. Molecular epidemiology of antibioticresistant Enterococcus spp. from the farm-to-fork continuum in intensive poultry production in KwaZulu-Natal, South Africa. Sci. Total Environ. 2019, 692, 868-878. [CrossRef] [PubMed]

18. CLSI. Performance Standards for Antimicrobial Susceptibility Testing, 30th ed.; CLSI: Wayne, PA, USA, 2020; CLSI M100-ED30.

19. EUCAST. Testing Breakpoint Tables for Interpretation of MICs and Zone Diameters, Version 10.0; Available online: www.eucast.org/ clinical_breakpoints / (accessed on 10 March 2020).

20. Krumperman, P.H. Multiple antibiotic resistance indexing of Escherichia coli to identify high-risk sources of fecal contamination of foods. Appl. Environ. Microbiol. 1983, 46, 165-170. [CrossRef] [PubMed]

21. Marti, R.; Scott, A.; Tien, Y.C.; Murray, R.; Sabourin, L.; Zhang, Y.; Topp, E. Impact of manure fertilization on the abundance of antibiotic-resistant bacteria and frequency of detection of antibiotic resistance genes in soil and on vegetables at harvest. Appl. Environ. Microbiol. 2013, 79, 5701-5709. [CrossRef] [PubMed]

22. Sengeløv, G.; Halling-Sørensen, B.; Aarestrup, F.M. Susceptibility of Escherichia coli and Enterococcus faecium isolated from pigs and broiler chickens to tetracycline degradation products and distribution of tetracycline resistance determinants in E. coli from food animals. Vet. Microbiol. 2003, 95, 91-101. [CrossRef]

23. Heuer, H.; Schmitt, H.; Smalla, K. Antibiotic resistance gene spread due to manure application on agricultural fields. Curr. Opin. Microbiol. 2011, 14, 236-243. [CrossRef] [PubMed]

24. Cools, D.; Merckx, R.; Vlassak, K.; Verhaegen, J. Survival of E. coli and Enterococcus spp. derived from pig slurry in soils of different texture. Appl. Soil Ecol. 2001, 17, 53-62. [CrossRef]

25. Garder, J.L.; Moorman, T.B.; Soupir, M.L. Transport and persistence of tylosin-resistant enterococci, erm genes, and tylosin in soil and drainage water from fields receiving swine manure. J. Environ. Qual. 2014, 43, 1484-1493. [CrossRef] [PubMed]

26. Müller, T.; Ulrich, A.; Ott, E.-M.; Müller, M. Identification of plant-associated enterococci. J. Appl. Microbiol. 2001, 91, 268-278. [CrossRef] [PubMed]

27. Micallef, S.A.; Goldstein, R.E.R.; George, A.; Ewing, L.; Tall, B.D.; Boyer, M.S.; Joseph, S.W.; Sapkota, A.R. Diversity, distribution and antibiotic resistance of Enterococcus spp. recovered from tomatoes, leaves, water and soil on U.S. Mid-Atlantic farms. Food Microbiol. 2013, 36, 465-474. [CrossRef] [PubMed]

28. Chen, Q.; An, X.; Li, H.; Su, J.; Ma, Y.; Zhu, Y. Long-term field application of sewage sludge increases the abundance of antibiotic resistance genes in soil. Environ. Int. 2016, 93, 1-10. [CrossRef] [PubMed]

29. Johnson, T.A.; Stedtfeld, R.D.; Wang, Q.; Cole, J.R.; Hashsham, S.A.; Looft, T.; Zhu, Y.-G.; Tiedje, J.M. Clusters of antibiotic resistance genes enriched together stay together in swine agriculture. MBio 2016, 7, e02214-e02215. [CrossRef] [PubMed]

30. Zhu, Y.-G.; Johnson, T.A.; Su, J.-Q.; Qiao, M.; Guo, G.-X.; Stedtfeld, R.D.; Hashsham, S.A.; Tiedje, J.M. Diverse and abundant antibiotic resistance genes in Chinese swine farms. Proc. Natl. Acad. Sci. USA 2013, 110, 3435-3440. [CrossRef] [PubMed]

31. Pyörälä, S.; Baptiste, K.E.; Catry, B.; van Duijkeren, E.; Greko, C.; Moreno, M.A.; Pomba, M.C.M.F.; Rantala, M.; Ružauskas, M.; Sanders, P.; et al. Macrolides and lincosamides in cattle and pigs: Use and development of antimicrobial resistance. Vet. J. 2014, 200, 230-239. [CrossRef] [PubMed]

32. McIver, K.S.; Amoako, D.G.; Abia, A.L.K.; Bester, L.A.; Chenia, H.Y.; Essack, S.Y. Molecular epidemiology of antibiotic-resistant Escherichia coli from farm-to-fork in intensive poultry production in KwaZulu-Natal, South Africa. Antibiotics 2020, 9, 850. [CrossRef]

33. Eagar, H.; Swan, G.; van Vuuren, M. A survey of antimicrobial usage in animals in South Africa with specific reference to food animals. J. S. Afr. Vet. Assoc. 2012, 83, 15-23. [CrossRef]

34. Furtula, V.; Jackson, C.R.; Farrell, E.G.; Barrett, J.B.; Hiott, L.M.; Chambers, P.A. Antimicrobial resistance in Enterococcus spp. isolated from environmental samples in an area of intensive poultry production. Int. J. Environ. Res. Public Health 2013, 10, 1020-1036. [CrossRef] [PubMed]

35. Kumar, K.; Gupta, S.C.; Baidoo, S.K.; Chander, Y.; Rosen, C.J. Antibiotic uptake by plants from soil fertilized with animal manure. J. Environ. Qual. 2005, 34, 2082-2085. [CrossRef] [PubMed]

36. Staley, C.; Breuillin-Sessoms, F.; Wang, P.; Kaiser, T.; Venterea, R.T.; Sadowsky, M.J. Urea amendment decreases microbial diversity and selects for specific nitrifying strains in eight contrasting agricultural soils. Front. Microbiol. 2018, 9, 634. [CrossRef] [PubMed]

37. Omar, S.A.; Ismail, M.A. Microbial populations, ammonification and nitrification in soil treated with urea and inorganic salts. Folia Microbiol. 1999, 44, 205-212. [CrossRef] [PubMed]

38. Byappanahalli, M.N.; Nevers, M.B.; Korajkic, A.; Staley, Z.R.; Harwood, V.J. Enterococci in the environment. Microbiol. Mol. Biol. Rev. 2012, 76, 685-706. [CrossRef] [PubMed] 
39. Thiele-Bruhn, S. Pharmaceutical antibiotic compounds in soils-A review. J. Plant. Nutr. Soil Sci. 2003, 166, 145-167. [CrossRef]

40. Popowska, M.; Rzeczycka, M.; Miernik, A.; Krawczyk-Balska, A.; Walsh, F.; Duffy, B. Influence of soil use on prevalence of tetracycline, streptomycin, and erythromycin resistance and associated resistance genes. Antimicrob. Agents Chemother. 2012, 56, 1434-1443. [CrossRef] [PubMed] 